\title{
O INCONSCIENTE SÓCIO-HISTÓRICO: APROXIMAÇÕES DE UM
} CONCEITO

\author{
EL INCONSCIENTE SOCIO-HISTÓRICO: ENFOQUES DE UN CONCEPTO \\ THE SOCIAL HISTORY UNCONSCIOUS: APPROACHES OF A CONCEPT
}

\author{
Lívia Gomes dos Santos \\ Pontifícia Universidade Católica de São Paulo, São Paulo/SP, Brasil
}

Inara Barbosa Leão

Universidade Federal do Mato Grosso do Sul, Campo Grande/MS, Brasil

\begin{abstract}
RESUMO
Um dos eixos centrais da Psicologia Sócio-histórica é o conceito de consciência. Entretanto, o psiquismo não pode ser igualado à consciência. Partindo dos pressupostos de Vigotsky, bem como de colaboradores e estudiosos de sua obra, analisamos como o inconsciente aparece dentro dessa vertente teórica e encontramos uma construção fundamentalmente diferente daquela usualmente presente na Psicologia. Percebemos o Inconsciente como uma construção cultural, resultado da organização da sociedade e, simultaneamente, social e individual. Ele só pode ser tomado como em constante relação com a consciência e caracteriza-se pela ausência de sentido e significado. É potencialmente consciente, o que se dá por meio da catarse; e assim como a consciência ele se manifesta nas ações dos indivíduos, caracterizando um comportamento desorientado, fragmentado, desconexo e de alguma forma limitante.
\end{abstract}

Palavras-chave: inconsciente; psicologia sócio-histórica; consciência.

\section{RESUMEN}

Uno de los conceptos centrales en la Psicología Sociohistorica es la concepción de consciencia. Entretanto, el psíquico no puede ser igualado a este concepto. Partimos de los presupuestos de Vigotski, así como de colaboradores y estudiosos de su obra, para hacer la análisis de lo inconsciente en esta corriente teórica y encontramos una construcción fundamentalmente diferente de aquella usualmente presente en la psicología. Percibimos el inconsciente como una construcción cultural, resultado de la organización de la sociedad y, simultáneamente, social e individual. Él solo puede ser comprehendido como en constante relación con la consciencia y se caracteriza por la ausencia de sentido y significado. Es potencialmente consciente, cuya conversión ocurre por medio de la catarse; y así como la consciencia se manifiesta en las acciones de los individuos caracterizando un comportamiento desorientado, fragmentado y de alguna forma limitante.

Palabras clave: inconsciente; psicologia sociohistórica; consciência.

\begin{abstract}
The concept of consciousness is central in Socio-historical psychology. However, the psyche can not be equated with consciousness. Based on the assumptions of Vygotsky, as well as employees and students of his work, we analyze how the unconscious appears within this theoretical model and find a building fundamentally different from that usually present in psychology. We realize the unconscious as a cultural construct, the result of organization of society and that is both social and individual. It can only be taken as constant in relation to consciousness and is characterized by the absence of meaning and significance. It is potentially conscious, which is through the catharsis, and awareness as well as it is manifested in the actions of individuals, characterizing behavior disoriented, fragmented, disjointed and somewhat limiting.
\end{abstract}

Keywords: unconscious; socio-historical psychology; consciousness. 


\section{Introdução}

A Psicologia Sócio-histórica é uma teoria de abordagem Materialista Histórico-dialética, cujo eixo central é o conceito de consciência e o entendimento dos homens como seres ativos que atuam sobre o mundo e, modificando-o, modificam a sua própria constituição subjetiva. $\mathrm{O}$ entendimento da consciência permite apreender o homem em sua multiplicidade, sem que ele seja reduzido a nenhum dos aspectos que compõem seu psiquismo e nem aos aspectos sociais que lhe são inerentes. Vigotsky ${ }^{1}$ (citado por Werstch, 1988) contempla duas direções que foram ignoradas por outros dentro da Psicologia: (a) a consciência possui um caráter histórico-social e deve ser concebida, a partir da relação que se estabelece entre o socialmente instituído e o que é próprio do sujeito; além disso, (b) não é possível conceber cada um dos processos ou funções psicológicas isoladamente, o que implica a exigência de um conceito que abarque todas as funções e processos e também considere o movimento que permite tal relação. A consciência aparece como possibilidade de análise da subjetividade, na qual seus elementos integrantes não são estanques e, consequentemente, o psiquismo não é cindido.

A consciência, portanto, deve ser entendida como um momento da dialética objetividade-subjetividadeobjetividade num processo contínuo e pautado pelas mediações. Ela se objetiva no comportamento do indivíduo, por meio da atividade. Essa objetivação só é completada quando o grupo apreende o comportamento emitido pelo sujeito e o significa, garantindo que sua ação configure-se novamente como significado, socialmente estabelecido e aceito. Vigotsky afirma que "a psique não existe fora do comportamento, assim como este não existe sem aquela, ainda que seja apenas por se tratarem do mesmo" (Vigotski, 2004, pp. 24-25).

Entretanto, Vigotsky (2004, p. 156) não iguala o conceito de psiquismo ao de consciência. Ao contrário, considera que

é preciso considerar esta (a psique) como parte integrante de um processo complexo que não se limita em absoluto à sua vertente consciente; por isso, consideramos que em psicologia é completamente lícito falar do psicologicamente consciente e inconsciente: o inconsciente é potencialmente consciente.

Já nessa citação é possível perceber que a forma como Vigotsky concebe o inconsciente é fundamentalmente diferente de como esta instância do psiquismo é usualmente tratada pela Psicologia.
O Inconsciente, conforme concebido pela Psicologia Sócio-histórica,

não está separado da consciência por alguma muralha intransponível. Os processos que nele se iniciam têm, frequentemente, continuidade na consciência e, ao contrário, recalcamos muito do consciente no campo do inconsciente. Existe uma relação dinâmica, viva e permanente, que nunca cessa, entre ambas as esferas da nossa consciência. O inconsciente influencia os nossos atos, manifesta-se no nosso comportamento, e por esses vestígios e manifestações aprendemos a identificar o inconsciente e as leis que o regem. (Vigotski, 1999, p. 82)

Portanto, consciente e inconsciente devem ser considerados como polos dialéticos, nos quais a existência de um possibilita e garante a existência do outro. O inconsciente não é mera ausência de consciência, mas só pode ser entendido como estando em permanente relação com ela. Assim como a consciência, o inconsciente se movimenta, é ativo, interage com todas as Funções Psicológicas Superiores e constitui-se um elemento a mais na dinâmica psíquica. E, tal como a consciência, é social, histórico e, ao mesmo tempo, é individual e singular pois depende das relações que o sujeito particular estabelece na realidade.

Pretendemos, ao longo deste artigo, evidenciar algumas das características do Inconsciente Sóciohistórico. Entendemos que a questão central do Inconsciente Sócio-histórico é a cultura. Portanto, para que possamos explicá-lo, iniciaremos evidenciando como os indivíduos resultam das relações concretas que estabelecem na realidade, que é sócio-historicamente constituída. Entendemos que o domínio da cultura é condição para a humanização, processo que pode ser entendido como a possibilidade dos sujeitos particulares usufruírem das conquistas da civilização e, com isso, satisfazerem suas necessidades tanto quanto desenvolver e exercitar as suas capacidades, podendo atuar ativamente na realidade (Martins \& Rabatini, 2011). Isso nos possibilitará evidenciar, num segundo momento, como a organização da nossa sociedade resulta na incapacidade de domínio de elementos da cultura, o que constitui o inconsciente.

\section{A constituição do indivíduo}

Ao adotarmos os pressupostos do Materialismo Histórico-dialético, entendemos que a realidade não está dada, mas é construída por meio da contínua transformação da natureza. A materialidade é anterior à consciência, e o mundo existe independentemente do indivíduo. Entretanto, ele atua sobre esse mundo 
e transforma-o para a satisfação de suas necessidades, num processo que culmina na transformação de si mesmo.

Tal entendimento resulta em conceber a realidade como sócio-historicamente determinada, uma vez que os condicionantes presentes na realidade resultam das diferentes formas de atuação do homem, cujo trabalho social, ao longo da história, resultou na construção de um ambiente que escapa às determinações naturais. O homem é, portanto, um ser que se caracteriza pela possibilidade de construir a própria existência. De acordo com Saviani (1991, pp. 96-97), transformar a natureza para a satisfação de suas próprias necessidades

\begin{abstract}
é a marca distintiva do homem, que surge no Universo, no momento em que um ser natural se destaca da natureza, entra em contradição com ela e, para continuar existindo, precisa transformá-la. ... O que se chama de desenvolvimento histórico não é outra coisa senão o processo através do qual o homem produz a sua existência no tempo. Agindo sobre a natureza, ou seja, trabalhando, o homem vai construindo o mundo histórico, vai construindo o mundo de cultura, o mundo humano.
\end{abstract}

Portanto, é o surgimento da cultura que possibilita ao homem passar a diferenciar-se dos demais animais. Sirgado (2000, p. 51) afirma que esse processo se caracteriza como um movimento de ruptura que "não interrompe o processo evolutivo, mas dá ao homem o comando da própria evolução. A história do homem é a história dessa transformação, a qual traduz a passagem da ordem da natureza à ordem da cultura".

É necessário que não percamos de vista que Vigotsky, seguindo a tradição do Materialismo Histórico-dialético, tem um conceito de cultura que

contraria, entre outras coisas, o costume tão difundido de reduzir o conceito de cultura a uma ou outra forma de produção, de preferência à produção estética (literatura, arte, folclore, etc.). Dizer que a cultura é o conjunto de produções humanas equivale a dizer que estamos diante de um conceito que engloba uma multiplicidade de coisas diferentes, que têm em comum o fato de serem constituídas dos dois componentes que caracterizam as produções humanas: a materialidade e a significação. (Sirgado, 2005, p. 92)

Portanto, quando falamos de cultura, estamos nos referindo a todas as transformações que o homem realiza, tanto na materialidade quanto na subjetividade, para o atendimento de suas necessidades e que passam a mediar a sua relação com essa realidade. Portanto, cultura compreende as transformações práticas da realidade, os instrumentos para desempenhá-las, os produtos gerados por essas práticas, as explicações sobre a realidade construída, as organizações sociais, etc. Tais construções também possuem caráter histórico, e, quando declaramos que o homem constrói o mundo de cultura, estamos afirmando que o homem rompe com a ordem natural e, ao invés de se submeter às determinações da natureza (como os outros animais), ele passa a transformar essa natureza em busca da satisfação de suas necessidades.

É necessário considerar que esse processo não é feito individualmente, mas pela coletividade, e que foi possibilitado pela emergência da atividade simbólica, que fez da atividade humana duplamente mediada pelos instrumentos técnicos e pelos simbólicos. De acordo com Leão (1999, pp. IX-X),

foi a criação e utilização de instrumentos físicos para suprir as limitações biofisiológicas da espécie humana, no trabalho de transformar a natureza para garantir a sobrevivência, que promoveu a constituição dos instrumentos psicológicos para complementarem as limitações para as atividades mentais necessárias à espécie. As principais características de ambos os tipos de instrumento é serem produtos socioculturais, criações artificiais.

O instrumento simbólico amplia as possibilidades da atuação prática, uma vez que possibilita que a atividade seja idealizada, planejada e até mesmo modificada sem nenhum tipo de atuação na materialidade.

A simbolização, cuja característica central é a possibilidade de "substituir realidades concretas por algo que não pertence ao real concreto, por realidades simbólicas" (Padilha, s.d., p. 1), possibilitou que a transformação realizada pelo homem na natureza fosse representada por meio de signos. Ou seja, as transformações realizadas pelos sujeitos materializaram-se sob a forma de construções culturais, ao mesmo tempo em que os sujeitos particulares puderam se apropriar dessas construções. É a significação, pois que possibilita que os membros da espécie humana organizem sua convivência e construam sua existência histórica (Sirgado, 2000).

A possibilidade de existência da consciência, portanto, está na linguagem. Isso significa que a consciência "é semioticamente estruturada, resultado dos próprios signos, ou seja, de instrumentos construídos pela cultura e pelos outros, que, quando internalizados, se tornam instrumentos subjetivos da relação do indivíduo consigo mesmo" (Aguiar, 2000, p. 130).

A linguagem, portanto, possibilitou o desenvolvimento de instrumentos internos, análogos aos instrumentos externos, e que possibilitam que o indivíduo atue na realidade circundante. Trata-se das 
Funções Psicológicas Superiores que, como afirma Vigotsky (2000, p. 29):

Se trata, en primer lugar, de procesos de dominio de los medios externos del desarrollo cultural y del pensamiento: el lenguaje, la escritura, el cálculo, el dibujo; y, en segundo, de los procesos de desarrollo de las funciones psíquicas superiores especiales, no limitadas ni determinadas con exactitud, que en la psicología tradicional se denominan atención voluntaria, memoria lógica, formación de conceptos etc.

A emergência do símbolo possibilitou que o externo fosse convertido em interno. Esse processo é necessário porque, enquanto nos outros animais a maior parte das informações necessárias para a sua existência está filogeneticamente estabelecida, ao homem é necessário que, no decurso de seu desenvolvimento ontogenético, ele se aproprie das construções historicamente desenvolvidas de forma a utilizá-las para a sua atuação na realidade; afinal, o homem produz a sua própria existência e quando nascemos é necessário que apreendamos aquelas construções culturais necessárias à sua sobrevivência em um contexto específico.

Entretanto, é necessário considerar que não se trata de uma cópia. A apropriação pressupõe a transformação daquele conteúdo antes de ele ser integrado à consciência. Tais modificações dependerão da atividade do sujeito que está em relação com os conteúdos socialmente produzidos e que tornará as produções sociais algo para si, possibilitando que participe da constituição de sua subjetividade.

Leontiev indica que, ao apropriar-se de determinado aspecto da cultura, o indivíduo forma faculdades específicas, que o caracterizam como humano. Segundo ele (2004, p. 286), para que ocorra a apropriação "dos objetos ou dos fenômenos, que são o produto do desenvolvimento histórico, é necessário desenvolver em relação a eles uma atividade que reproduza, pela sua forma, os traços essenciais da atividade encarnada, acumulada no objeto".

A linguagem é uma construção cultural e, portanto, a subjetividade não pode ser compreendida de maneira isolada. A única possibilidade está em considerar o ambiente sócio-histórico no qual o sujeito participa e que influirá nos conteúdos da cultura que serão disponibilizados para os sujeitos particulares. Isso resulta também na determinação de como se dá a apropriação, qual a estrutura e o funcionamento das Funções Psicológicas Superiores, etc.. A composição e a organização do psiquismo são construções históricas e, portanto, socialmente estabelecidas, influindo também na dinâmica entre o inconsciente e a consciência.
Para Vigotsky (citado por Sirgado, 2000), as formas superiores de comportamento do homem são derivadas das condições proporcionadas pela prática social e suas concepções organizadas, que constituem a cultura. Dessa forma, as Funções Psicológicas Superiores foram formadas ao longo da história social da humanidade e dependem do contexto sócio-histórico no qual são criadas, para atenderem às necessidades dos grupos que as originam. Como afirma Leontiev (2004, p. 94), "ela adquire particularidades diversas segundo as condições sociais da vida dos homens e transformase na sequência do desenvolvimento das suas relações econômicas". É necessário considerar, portanto, que vivemos em uma sociedade marcada pela divisão de classes, a qual condiciona a forma de transmissão da cultura e, consequentemente, apropriada pelos sujeitos particulares.

Considerando essa forma diferenciada de apropriação da cultura, de acordo com a classe social, existem alguns conteúdos que participam da estrutura do psiquismo, permanecendo como força influente na avaliação da realidade para o direcionamento da ação. Contudo, não se apresentam como argumentos conscientes, pois o indivíduo não tem o domínio da cultura que lhe permite a elaboração dos sentidos e significados de tal conteúdo, o que caracterizaria o controle consciente.

Para que possamos prosseguir, é mister que nos detenhamos brevemente na discussão de como a consciência é formada, a partir da síntese estabelecida entre significado e sentido. Isso porque é necessário explicitar como a consciência se constitui, para que evidenciemos as características dos conteúdos inconscientes do psiquismo. Não estamos com isso afirmando que o inconsciente se caracteriza pela mera ausência de consciência; mas não podemos perder de vista que ambos mantêm "uma relação de mediação, na qual um não se dilui no outro, cada qual mantendo sua identidade, ainda que um não exista sem o outro. Pode-se afirmar, portanto, que o inconsciente é parte constitutiva da consciência e vice-versa" (Aguiar, 2000, p. 137).

Logo, não é possível considerar o inconsciente senão em relação com a consciência.

\section{A dialética consciência-inconsciência}

A consciência pode ser compreendida como os conteúdos e processos subjetivos que permitem ao indivíduo se relacionar no ambiente material e social. Vigotsky (2004) procurou uma unidade de análise do comportamento humano que fosse capaz 
de incluir todas as manifestações psicológicas, das mais simples (como a memória) às mais complexas (como a identidade). Encontrou essa possibilidade no significado, ou seja, o princípio que organiza o desenvolvimento da consciência. Significado é aquilo que aparece objetivamente no sistema de relações: é a palavra conforme está no dicionário, o conceito conforme definido em um meio científico reconhecido socialmente (Leão, 1999). Ele representa as percepções acerca da realidade sócio-histórica na qual se está inserido e indica os limites e possibilidades da representação dessa realidade. Significado é, portanto, social.

De acordo com Leontiev (2004, p. 102),

a significação é o reflexo da realidade independentemente da relação individual ou pessoal do homem a esta. O homem encontra um sistema de significações pronto, elaborado historicamente, e apropria-se dele tal como se apropria de um instrumento, esse precursor material da significação. $\mathrm{O}$ fato propriamente psicológico, o fato da minha vida, é que eu me aproprie ou não, que eu assimile ou não uma dada significação, em que grau eu a assimilo e também o que ela se torna para mim, para a minha personalidade; esse último elemento depende do sentido subjetivo e pessoal que essa significação tenha para mim.

Dessa forma, o sentido é a subjetivação do significado, a individualização que permite a uma mesma palavra um único significado, mas sentidos diversos para cada indivíduo. $\mathrm{O}$ sentido refere-se à soma de todos os eventos psicológicos que cada palavra representa para cada um de nós. Isso ocorre porque a experiência individual da prática social medeia a realidade que aparece em sua significação social. O sentido é carregado de componentes afetivos e sociais que medeiam a relação do indivíduo com a realidade. Assim, o sentido reorganiza a consciência, ao definir quais as funções necessárias à dada atividade, quais comportamentos emitir, quais estímulos selecionar, enfim, como portar-se diante do ambiente que está apresentado em um momento específico.

A consciência é, portanto, formada quando o indivíduo, por meio da atividade, entra em contato com os significados sócio-historicamente desenvolvidos e apreende a realidade, de maneira ativa, criativa, sobre a base e no decorrer da transformação prática da realidade; essa apreensão caracteriza-se pela atribuição de um sentido àquele conteúdo determinado.

É necessário considerar que o sentido não nega o caráter social da consciência, o que pode ser explicado por dois motivos complementares: (a) o significado do qual o sujeito se apropria por meio de sua atividade é socialmente estabelecido e decorre das características presentes no contexto em que ele está inserido, principalmente do modo de produção da vida em diferentes épocas, das instituições, etc. Diferentes contextos implicarão diversas formas de explicação da realidade. Portanto, os sentidos que serão construídos pelos indivíduos, no decorrer das suas atividades, são únicos por serem ligados à própria relação com a realidade, mas dependem daquelas explicações sociais condensadas nos significados. O significado existe objetivamente independente dos sujeitos particulares. Entretanto, no indivíduo ele só integra a consciência quando the é atribuído um sentido.

Por isso, não há sentido sem significado, e não há uma explicação individual para conteúdos não contemplados pelo grupo social no qual o sujeito está inserido. Em outros termos, a sociedade oferece as possibilidades e também os limites das explicações individuais para a realidade. Além disso, (b) a síntese estabelecida entre o sentido e o significado precisa ser objetivada, sob a forma de comportamento e referendada por aqueles que compõem o mesmo grupo social, para se caracterizarem como aspecto consciente do psiquismo. Quando tais objetificações são reprimidas pela sociedade, elas passam a compor o inconsciente. Lane (1995, p. 60) indica essa possibilidade ao se perguntar se

o inconsciente não seria também um produto histórico que surge em nossa sociedade, a partir do momento em que se dá a cisão entre o homem público e o privado, levando à repressão emocional cuja manifestação deveria se dar na privacidade. O homem público é por excelência o ser racional. E Freud, vivendo na era vitoriana, só poderia captar a liberdade tão reprimida nesse período, presente no inconsciente.

Assim, a mediação do grupo é determinante na constituição da consciência individual. Portanto, termina por eleger também quais conteúdos serão conscientes e quais não terão tal qualidade. Isso porque, se estamos tomando a consciência como apropriação dos conteúdos da cultura e que se organizam no psiquismo pela forma de significado e sentido, é a ausência desses elementos que caracteriza o inconsciente. Inconsciente é derivado da materialidade das relações que cada indivíduo estabelece no meio circundante, e é relacionado àqueles conteúdos presentes sob a forma de tônus emocional, mas que não podem ser explicados, transformados em sentido e significado. Portanto, o inconsciente é definido pela falta do elemento semiótico que caracteriza a consciência.

Isso porque é necessário considerar que a significação da realidade não existe abstratamente, 
mas no outro, que já se apropriou de alguns aspectos da cultura e, portanto, tem a possibilidade de servir como mediador para aqueles que ainda não a possuem, objetivando aquilo que ele sabe para que quem não sabe possa subjetivar.

Isso evidencia que a apreensão da cultura só é possível por meio da realização de um processo educacional, no qual um sujeito que detém o domínio sobre aquele aspecto da cultura transmite-o aos demais. Por exigir a compreensão da complexidade da cultura e sua transmissão, que atende também aos interesses de grupos e classes hegemônicas da sociedade, a Educação é um processo mediacional, cujo objetivo é transformar o indivíduo, inicialmente um ser biofisiológico, em um ser social (Leontiev et al., 2005). Esse processo é uma particularidade dos seres humanos, que nascem num sistema complexo de relações sociais, e nesse sistema social irão interiorizar os aspectos que lhe permitirão estabelecer-se no ambiente, que, no caso dos seres humanos, é socialmente determinado, construído (Leão, 1999).

Embora os limites desta apresentação nos impeçam de aprofundar tal discussão, destacamos que a Educação possui uma intrínseca relação com o inconsciente, podendo afirmar que

o fato da educação desenvolver a consciência é a principal constatação da forma que o inconsciente sócio-histórico relaciona-se com a educação. Ela permite a apropriação da cultura, portanto instrumentaliza ... Torna o social em individual e permite o movimento contrário, que é a objetivação da subjetividade. A educação, portanto, diminui o inconsciente, e também determina o seu conteúdo. (Santos, 2010, pp. 243-244)

Isso ocorre porque a consciência depende de como os conteúdos culturais foram transmitidos pela sociedade e apropriados pelos sujeitos particulares. Em alguns momentos, não será possível atuar na construção dos sentidos, o que impossibilitará a apropriação dos significados. Tais conteúdos permanecerão inconscientes, pois, apesar de existir na realidade, o indivíduo não tem condições de utilizálos na orientação consciente de sua prática. Essa impossibilidade de apropriação se dá pela divisão da sociedade em classes, pela forma com que a escolarização (que é a educação institucionalizada) é realizada, pela impossibilidade que o trabalhador tem, no capitalismo, de participar das construções culturais. Enfim, pela forma como a nossa sociedade é organizada.

Isso ocorre porque fazemos parte de uma sociedade na qual alguns conteúdos são cultural e socialmente negados a alguns grupos, o que faz com que alguns conteúdos do inconsciente jamais cheguem à consciência, porém continuam a existir e atuar sobre a sociedade, e, consequentemente, também nos indivíduos. Essa negação ocorre quando a estruturação da sociedade faz com que os sujeitos, primordialmente os da classe trabalhadora, não tenham acesso às construções culturais que possibilitariam o desenvolvimento das Funções Psicológicas Superiores. Objetivando construir um tipo específico de homem, as instituições acabam por determinar quais conteúdos e processos são necessários; em contrapartida, também caracterizam aqueles que não o serão, fazendo com que não possam fazer parte da constituição psíquica consciente desses sujeitos.

Consideramos que a consciência se refere à possibilidade de compreender e atuar na realidade circundante. Ela se manifesta no comportamento orientado, direcionado, capaz de satisfazer às necessidades de quem o realiza. $O$ inconsciente também se manifesta no comportamento, mas sob a forma de impossibilidade: o sujeito faz sem saber o porquê. Tendo mais conteúdos inconscientes, ele acaba sendo dominado por essa realidade, ao invés de utilizar-se dela para satisfação de suas necessidades.

Entendidos alguns aspectos da relação com a consciência e de como o inconsciente é resultado das condições reais estabelecidas na materialidade, é necessário que nos ocupemos com a caracterização dessa instância do psiquismo.

\section{O inconsciente sócio-histórico}

Alguns autores apontam a entrada de Vigotsky na Psicologia por meio de suas investigações no campo da Arte e, mais particularmente, da Literatura (Molon, 2003; Van Der Veer \& Valsiner, 2009). Suas primeiras investigações referem-se à busca da compreensão dos mecanismospsicológicos envolvidos nacriaçãoartística e nas funções específicas da Arte. Molon (2003, p. 22) indica que esse autor tinha "uma preocupação com a origem do homem e da cultura e revelava seu interesse pelos mecanismos psicológicos da criação artística, literária e das questões semiológicas pertinentes aos símbolos, signos e imagens poéticas". Entre as discussões estabelecidas por Vigotsky (1999) nessa obra, já estavam presentes as primeiras construções acerca do inconsciente; para ele, apreender a Arte limitando-se à vivência consciente seria uma maneira absolutamente limitada e que não poderia oferecer todas as respostas às questões que a Arte suscitava.

Entretanto, Vigotsky deixa claro que concebe o inconsciente de uma forma fundamentalmente diferente 
da forma como ele é tratado pela Psicanálise, que se constitui como a principal teoria acerca dessa instância do psiquismo. Para Vigotsky (1999, pp. 92-93), a psicanálise é organizada por um pansexualismo que

\begin{abstract}
parece absolutamente infundado ... Talvez isso fosse verdadeiro para o homem visto fora da sociedade, isolado no estreito círculo dos seus próprios instintos. Entretanto, como podemos aceitar que no homem social, que participa de formas muito complexas de atividade social, não possa surgir e existir toda sorte de outras atrações e aspirações, que determinem o seu comportamento não menos que as atrações sexuais e inclusive exerçam domínio sobre ele? ... De fato, ao apontarem o papel excessivamente importante do inconsciente, os psicanalistas reduzem a absolutamente nada toda consciência que, segundo expressão de Marx, constitui a única diferença entre o homem e o animal.
\end{abstract}

Portanto, o inconsciente, assim como qualquer outro aspecto do psiquismo, deve ser tomado partindo de sua historicidade, das condições concretas estabelecidas na sociedade e que interferem na constituição da subjetividade dos indivíduos particulares, enfim, da materialidade das determinações culturais que criam tal inconsciente e que também oferecem as possibilidades de entendê-lo e superá-lo.

Ainda nessa obra, Vigotsky busca uma explicação do mecanismo que origina o Inconsciente. Ele afirma que existem sentimentos que são vividos como afetos presentes na atividade do indivíduo, mas que não se reobjetivam por meio do comportamento. São inúmeros os estímulos que chegam até o sistema nervoso, mas apenas alguns deles vão ganhar caráter consciente. Ele (1999, pp. 312-313) indica que

\begin{abstract}
Nosso organismo está estruturado de tal modo que seus campos receptores nervosos superam em muito os seus neurônios eferentes, resultando daí que o nosso organismo percebe muito mais atrações e estímulos do que pode realizar. ... O sistema nervoso lembra um campo de batalha permanente, e nosso comportamento realizado representa apenas uma ínfima parte do que existe em forma de possibilidade, que foi acionado mas não encontrou vazão. Como na natureza a parte realizada da vida representa uma parcela ínfima de toda a vida que poderia ter surgido, como cada vida que nasce deve-se a milhões de vidas que não nascem, assim, no nosso sistema nervoso, a parte da vida realizada supõe a parte menor da realmente contida em nós. ... O organismo foi colocado em certo equilíbrio com o meio, é necessário regular a balança como é necessário abrir a válvula na caldeira em que a pressão do vapor supera a resistência do seu corpo.
\end{abstract}

Com isso, Vigotsky indica que milhares de estímulos chegam ao nosso organismo, e a maior parte deles não se torna consciente. Entretanto, esses estímulos atingiram o indivíduo e, enquanto não são objetivados, ou objetificados (tornados um produto social), tais afetos permanecem inconscientes. Eles são vividos como angústia e precisam ser solucionados; e entre os recursos para essa solução estão as palavras e a Arte.

Esse processo de passagem do inconsciente para o consciente caracteriza-se por ser uma catarse, que pode ser definida como a solução do conflito pela a criação de algo novo, devido à descarga de energia do conflito em um objeto social. De acordo com Sawaia, a catarse

não é apenas a descarga de sentimentos com a sua consequente tranquilização. Ela se caracteriza pelo confronto de paixões contrárias, que gera a complexa transformação dos sentimentos. A arte suscita em nós emoções voltadas a sentidos opostos ao habitual e, ao pôr em choque impulsos contrários, destrói paixões, acarretando a complexa transformação dos sentimentos. (Vigotski, 1998, p. 270, citado por Sawaia, 2009, p. 369)

Portanto, não se trata de uma transposição de um ao outro pólo, mas de uma modificação, na qual o conteúdo inconsciente é alterado, transformado e agrega-se aos aspectos conscientes da vida do sujeito.

Vigotsky (2004) também abordou o inconsciente quando discutia a questão do método em Psicologia. Ao contrário de outras vertentes que tomavam o inconsciente ora como psicológico, ora como exclusivamente fisiológico, Vigotsky afirmava que em uma psicologia dialética essa divisão não tem razão de se manter, uma vez que

o ponto de vista dialético afirma que o inconsciente não é nem psíquico nem fisiológico, mas psicofisiológico, ou, sendo mais exatos, psicológicos. Essa definição ajusta-se à autêntica natureza e às autênticas características do objeto, já que consideramos todos os fenômenos de comportamento como processos integrais. (Vigotski, 2004, p. 157)

O aspecto biológico que caracteriza o Inconsciente é a ausência de transmissão de reflexo. De acordo com essa concepção, o desencadeamento fisiológico de um determinado afeto é a transmissão de um sistema para outro. Assim,

devemos compreender, antes de mais nada, a própria consciência ou a conscientização por nossa parte dos atos e estados próprios como um sistema de mecanismos transmissores de uns reflexos para outros, que funciona perfeitamente em todo momento consciente. ... Dar-se conta de algo significa justamente transformar certos reflexos em outros. $\mathrm{O}$ inconsciente, o psíquico, implica que o s reflexos não se transmitem a outros sistemas. (Vigotski, 2004, p. 71) 
O que impede que determinado reflexo seja transmitido é a ausência do elemento semiótico que permite a conversão do reflexo em uma explicação. Portanto, outro importante aspecto a ser considerado no entendimento do inconsciente é a cultura. Para a Psicologia Sócio-histórica, a cultura tem importância determinante, como destacamos anteriormente, e é condição para que possamos compreender como se estrutura o Inconsciente.

Embora tenhamos uma base biológica que não pode ser desconsiderada, essa é reorganizada, alterada e, em última instância, subordina-se às determinações culturais.

Nesse entendimento, a consciência deve ser considerada como um sistema semioticamente estruturado, mas que depende da base material do cérebro para se desenvolver. A estrutura cerebral permite o desenvolvimento do psiquismo, tanto em seu aspecto consciente quanto no inconsciente, mas não é capaz de explicá-los.

Para Vigotsky (2004), tomar consciência é transferir determinada operação para o plano da linguagem, possibilitando exprimi-la em significados socialmente estabelecidos. Trata-se, portanto, do movimento de transformação da objetividade em subjetividade, em um processo que permite que a atividade externa seja transformada em atividade interna, que é simbolizada pelos conceitos. Tal transformação permite que o sujeito apreenda a forma como o meio o está afetando e, a partir disso, ele possa agir sobre esse meio em busca da satisfação de suas necessidades, num processo contínuo de alteração da realidade e de si mesmo. $\mathrm{O}$ inconsciente se caracteriza justamente por essa incapacidade de simbolizar a própria experiência. A ausência da mediação semiótica, que caracteriza o inconsciente, faz com que o objeto permaneça continuamente sob a forma de estímulo, ao qual o sujeito não sabe como reagir por não possuir o conteúdo cultural que o possibilitaria fazê-lo.

Entretanto, esses conteúdos foram interiorizados $\mathrm{e}$, ainda que como uma marca neurológica, existem no psiquismo e passam a influir no comportamento. A impossibilidade de conversão em significado faz com que permaneçam como tônus emocional. O tônus é

\footnotetext{
uma avaliação da atividade [que] é anterior à reflexão cognitiva das relações que promoveu. Dá-se ainda no nível da representação sensorial direta da situação ou do pensamento e, portanto, está baseada no sentimento que permite apenas a vivência do que foi sentido emocionalmente. (Leão, 1999, p. 63)
}

Isso evidencia que, quando permanecem sob a forma de tônus emocional, os conteúdos que foram interiorizados atuam no comportamento sem que o sujeito consiga explicar porque o faz. Existe um direcionamento do indivíduo a determinado objeto, quando o tônus emocional é positivo, e uma tendência a afastar-se dele quando o tônus é negativo. Essa escolha não pode ser explicada pelo sujeito por duas razões: (a) porque ele não dispõe dos conteúdos culturais que o possibilitaria fazê-lo e (b) porque em alguns casos faltam os processos psicológicos que permitam a atividade psíquica.

Tais considerações nos permitem constatar que a afetividade aparece como uma mediadora fundamental do inconsciente. Ela sintetiza os elementos culturais, sociais e individuais envolvidos em determinado fenômeno e, como tal, atua na relação do sujeito no mundo. Como afirma Banchs (1995, p. 108), as emoções "mediatizam a informação que selecionamos do ambiente, acentuando alguns aspectos e fazendo com que outros permaneçam no nível subliminar. Elas podem facilitar ou inibir o acesso consciente às informações que estão ao alcance das mãos". Sawaia $(2000$, p. 15) destaca que "afetividade é o nome atribuído à capacidade humana de elevar seus instintos à altura da consciência, por meio dos significados, de mediar a afecção pelos signos sociais, aumentando ou diminuindo nossa potencia de ação".

Isso significa que a afetividade direciona o indivíduo, de acordo com as condições concretas que ele estabelece na realidade e com o objetivo de atender às exigências suscitadas nessa relação. Nesse direcionamento, ela elege quais são os conteúdos disponíveis na consciência e que podem atender a tal necessidade, e também resgata aqueles conteúdos inconscientes cuja construção cultural está disponível ao indivíduo; transforma-o, portanto, em consciente, por meio do processo catártico explicado anteriormente. Quando aquele conteúdo cultural não está presente, a afetividade continua a direcionar o indivíduo, mas ele não tem a condição de se apoiar nas construções culturais que lhe garantiriam a realização de um comportamento assegurasse a satisfação das necessidades suscitadas. Assim, o sujeito faz, mas não sabe por quê; ele repete, copia, reproduz, mas não tem a possibilidade de criar algo novo, de transformar.

\section{O inconsciente sócio-histórico: aproximações de um conceito}

Ao longo deste artigo, buscamos evidenciar como se caracteriza o inconsciente a partir de uma perspectiva Materialista Histórico-dialética. Demonstramos que assim como qualquer outro aspecto do psiquismo 
o Inconsciente é social e histórico, dependendo do contexto no qual o sujeito está inserido e das relações estabelecidas por ele ao longo da vida. Justamente por isso, por ser desenvolvido a partir das condições reais de existência, é completamente passível de transmutarse em consciente por meio de um processo catártico, de transformação. Essa catarse é possível, quando o inconsciente se materializa em conteúdos culturais, seja a Arte, a palavra ou qualquer outra produção que possibilite ao sujeito objetivar sua subjetividade e, por meio desse processo, consiga atuar na realidade de maneira ativa e criativa que possibilite a verdadeira transformação.

Isso porque, quando os comportamentos são guiados primordialmente pelo inconsciente, ele se caracteriza por ser limitante, repetitivo. Consideramos que não existe possibilidade de transformação social sem criatividade, e a criatividade só é possível com a consciência, com o domínio da cultura. Uma atuação transformadora só pode ser realizada, partindo das construções culturais já existentes e que são mais elaboradas, permitindo um entendimento e uma modificação expressiva do contexto em busca da satisfação de suas necessidades e das de seu grupo social.

Não podemos perder de vista o fato de que a condição para esse processo é a mediação social, que assegura aos sujeitos a cultura e garante tal transformação. Em uma sociedade que, como a nossa, caracteriza-se pelo individualismo exacerbado, esse processo é continuamente impossibilitado. Pelo contrário, os indivíduos tendem a não se reconhecer mais como membros de uma mesma classe social e, portanto, não se relacionam senão para a satisfação de suas próprias necessidades; o que demonstra que, apesar de terem problemas semelhantes não conseguem uma interação e uma atuação conjunta. É necessário superar essa realidade. É preciso superar as condições materiais que criam uma atuação que não responde às necessidades do sujeito; é preciso superar as condições que criam um comportamento que reflete a própria consciência: fragmentado, desconexo, de alguma forma limitante.

\section{Nota}

1 Por se tratar de um nome russo, o nome deste autor recebeu diferentes grafias nas diferentes traduções para o nosso alfabeto: Vigotski, Vigotskii, Vygotsky e Vigotsky são apenas algumas delas. Optamos por utilizar Vigotsky, respeitando, no entanto, nas citações, a grafia original das obras referenciadas.

\section{Referências}

Aguiar, W. M. J. (2000). Reflexões a partir da psicologia sócio-histórica sobre a categoria "consciência". Cadernos de Pesquisa, 110, 125-142. Acesso em 30 de agosto, 2007, em http://www.scielo.br/scielo.php?script=sci arttext\&pid $=$ S0100-15742000000200005\&lng=pt\&nrm=iso

Banchs, M. A. (1995). O papel da emoção na representação do self e do outro em membros de uma família incestuosa. In S. T. M. Lane \& B. Sawaia (Orgs.), Novas veredas da Psicologia Social (pp. 97-113). São Paulo: Brasiliense.

Lane, S. T. M. (1995). A mediação do emocional na constituição do psiquismo humano. In S. T. M. Lane \& B. Sawaia (Orgs.), Novas veredas da Psicologia Social (pp. 55-63). São Paulo: Brasiliense.

Leão, I. B. (1999). Os professores universitários: a emoção e o pensamento em um trabalho intelectual institucionalizado. Tese de Doutorado, Programa de Pós-graduação em Psicologia Social, Pontifícia Universidade Católica/SP, São Paulo.

Leontiev, A. O desenvolvimento do psiquismo. (2004). São Paulo: Centauro.

Leontiev, A., Vygotsky, L. S., Luria, A. R. et. al. (2005). Psicologia e Pedagogia - bases psicológicas da aprendizagem e do desenvolvimento. São Paulo: Centauro.

Martins, L. M. \& Rabatini, V. G. (2011). A concepção de cultura em Vigotski: contribuições para a educação escolar. Revista Psicologia Política, 11(22), 345-358.

Molon, S. I. (2003). Subjetividade e constituição do sujeito em Vygotsky. Petrópolis, RJ: Vozes.

Padilha, A. M. L. (s.d.). A linguagem e a formação da consciência: uma perspectiva histórico-cultural. Salto para o Futuro, 1(1), 39-42. Acesso em 18 de janeiro, 2010, em http://www.unimep.br/ ampadilh/a-linguagem-e-aformacao.pdf

Santos, L. G. (2010). Educação e o Inconsciente Sócio-histórico: uma análise da função da escolarização na construção de sentidos e significados do desemprego. Dissertação de Mestrado, Universidade Federal de Mato Grosso do Sul, Campo Grande.

Saviani, D. (1991). Pedagogia Histórico-crítica: primeiras aproximações. São Paulo: Autores Associados / Editora Cortez.

Sawaia, B. B. (2000). A emoção como lócus da produção do conhecimento: uma análise centrada em Espinosa e Vygotsky. In Anais da III Conferência de Pesquisa Sóciocultural. Acesso em 30 de agosto, 2007, em http://www.fae. unicamp.br/br2000/trabs/1060.doc

Sawaia, B. B. (2009). Psicologia e desigualdade social: uma reflexão sobre liberdade e transformação social. Psicologia \& Sociedade, 21(3), 364-372. Acesso em 06 de dezembro, 2011, em http://www.scielo.br/pdf/psoc/v21n3/a10v21n3. pdf

Sirgado, A. P. (2000, julho). O social e o cultural na obra de Vigotski. Educação \& Sociedade, 21(71), 4578. Acesso em 18 de janeiro, 2010, em http://www. scielo.br/scielo.php? script $=$ sci arttext\&pid $=\mathrm{S} 0101$ 73302000000200003\&lng=en\&nrm=iso

Sirgado, A. P. (2005). As marcas do humano: as origens da constituição cultural da criança na perspectiva de Lev $S$. Vigotski. São Paulo: Cortez. 
Van Der Veer, R. \& Valsiner, J. (2009). Vygotsky: uma síntese ( $6^{\mathrm{a}}$ ed.). São Paulo: Edições Loyola.

Vigotski, L. S. (1999). Psicologia da arte. São Paulo: Martins Fontes.

Vygotski, L. S. (2000). Obras escogidas (Vol. 3). Madrid: Visor. Vigotski, L. S. (2004). Teoria e método em Psicologia ( $3^{\mathrm{a}}$ ed.). São Paulo: Martins Fontes.

Wertsch, J. V. (1988). Vygotsky y la formación social de la mente. Barcelona: Paidós.

Submissão em: 06/07/2012

Aceite em: 06/04/2014

Livia Gomes dos Santos é psicóloga, mestre em educação pela Universidade Federal de Mato Grosso do Sul, doutoranda em Psicologia: Psicologia Social pela PUC-SP. Membro do GEPAPET - Grupo de Estudos e Pesquisa sobre os Aspectos Psicossociais da Educação e do Trabalho, coordenado pela Profa. Dra. Inara Barbosa Leão; e do NEXIN - Núcleo de Estudos e Pesquisas sobre a Dialética Exclusão/Inclusão, sob a coordenação da Profa. Dra. Bader B. Sawaia. Endereço: Rua Capitão Otávio Machado, 950 - apto. 11b Chácara Santo Antonio, São Paulo, SP E-mail: liviagomess@hotmail.com

Inara Barbosa Leão é psicóloga, Doutora em Psicologia (Psicologia Social) pela Pontifícia Universidade Católica de São Paulo (PUC-SP). Professora no Ensino de $3^{\circ}$ Grau, na Universidade Federal de Mato Grosso do Sul, nos cursos de Graduação Formação de Psicólogo. Professora nos Cursos de Pós-Graduação de Mestrado e Doutorado em Educação na Universidade Federal de Mato Grosso do Sul (UFMS). Coordenadora do GEPAPET - Grupo de Estudos e Pesquisa sobre os Aspectos Psicossociais da Educação e do Trabalho. E-mail: inarableao@hotmail.com 